\title{
Faktor yang Berkaitan dengan Tahapan Adopsi Petani terhadap Teknologi Mesin Rice Transplanter (Kasus pada Enam Subak di Kabupaten Tabanan)
}

\author{
PUTU ICHIRO FUJIARTA, I DEWA GEDE RAKA SARJANA, \\ I GEDE SETIAWAN ADI PUTRA \\ Program Studi Agribisnis Fakultas Pertanian Universitas Udayana \\ J1. PB. Sudirman Denpasar 80232 \\ Email : ichiro_arta1@yahoo.com \\ idewagederakasarjana@yahoo.com
}

\section{Abstract \\ Factors Related to the Stages of Farmer Adoption of Rice Transplanter Machine Technology (A Case in Six Subaks in Tabanan Regency)}

Rice transplanter is a modern machine for planting rice seeds. The provision of the machine is to support the government program. The purpose of this study was to determine the extent of adoption and factors related to the adoption of rice transplanter machine. The research locations were in six subaks in Tabanan Regency using 89 respondents. The method used was qualitative descriptive analysis and scoring scale measurement.

Based on the research result of adoption stage of rice transplanter machine has reached the implementation stage to be tested. Factors related to technology adoption, namely the nature of innovation that is known to be true as $88.76 \%$ of respondents. Farmers' perceptions of the usefulness and benefits of technology are quite good (score 758 including class > 695-909) and perceptions of ease of technology are quite difficult (score 726 including class > 695-909). The target attitude wants to implement and the need for technology is very low (a score of 155 and a score of 143 is included in classes 89-160). The target behavior in accepting innovation was low, only $12.36 \%$ of respondents received. For the use of innovation, only $12.36 \%$ of respondents used innovation to try.

Keywords: adoption, rice transplanter, technology

\section{Pendahuluan}

\subsection{Latar Belakang}

Upaya khusus (UPSUS) terus dilaksanakan serta berbagai program bantuan pemerintah dalam bidang pertanian terus digelontorkan untuk mendukung tercapainya swasembada. Seiring dengan semakin meningkatnya jumlah penduduk di Indonesia yang sampai dengan saat ini telah mencapai 254,9 juta orang (BPS, 2015) maka kecukupan bahan pangan menjadi sangat penting untuk diperhatikan. Program UPSUS berupaya melakukan peningkatan produktivitas dan indeks pertanaman melalui ekstensifikasi berupa pencetakan sawah baru dan intensifikasi berupa peningkatan 
ketersediaan air irigasi, benih, pupuk, dan penyediaan alat dan mesin pertanian (alsintan) terus dilaksanakan.

Direktorat Jenderal Prasarana dan Sarana Pertanian mengalokasikan anggaran dalam APBN 2017 untuk penyediaan alsintan pra-panen untuk mempercepat pengolahan tanah berupa traktor roda dua dan traktor roda empat, alsintan berupa pompa air dan mini excavator, rice transplanter, cultivator serta Hand Sprayer. Program upsus dilaksanakan serentak di beberapa provinsi di Indonesia. Pada Provinsi Bali, khususnya di wilayah Kabupaten Tabanan mendapatkan sejumlah bantuan alsintan berupa pompa air, traktor roda dua dan mesin rice transplanter. Untuk bantuan mesin rice transplanter ada enam subak di Kabupaten Tabanan yang mendapat bantuan mesin.

Bantuan mesin rice transplanter diharapkan diimplementasikan oleh petani bantuan pada lahan usahatani. Teknologi mesin rice transplanter jika diadopsi oleh petani sangat menguntungkan, karena dapat memudahkan dalam penanaman bibit padi, lebih mempercepar waktu pekerjaan, efektif, dan juga menghemat biaya produksi untuk proses penanaman (Kardasan, 2011). Diharapkan petani yang menjadi penerima bantuan mengimplementasikan teknologi mesin rice transplanter, tetapi untuk riilnya dilapangan belum dimaksimalkan pengimplementasiannya. Hal tersebut disebabkan beberapa faktor yang berkaitan diantaranya adalah sifat inovasi, persepsi, perilaku, sikap, dan penggunaan inovasi. Faktor-faktor tersebut sangat berpengaruh terhadap adopsi teknologi mesin rice transplanter pada usahatani petani.

Berdasarkan uraian tersebut, menarik untuk dikaji tentang faktor yang berkaitan dengan tahapan adopsi petani terhadap teknologi mesin rice transplanter (kasus pada enam subak di Kabupaten Tabanan)

\subsection{Tujuan}

Tujuan penelitian ini adalah sebagai berikut.

1. Mengetahui sejauhmana tahapan adopsi petani terhadap teknologi mesin rice transplanter di enam subak di Kabupaten Tabanan.

2. Mengetahui faktor apa saja yang berkaitan dengan tahapan adopsi petani terhadap teknologi mesin rice transplanter di enam subak di Kabupaten Tabanan.

\section{Metode Penelitian}

\subsection{Lokasi dan Waktu Penelitian}

Penelitian ini dilaksanakan selama lima bulan yakni dari bulan Januari 2018 sampai Mei 2018. Penelitian ini dilaksanakan di Subak Kesiut, Subak Lumbung, Subak Merta Sari, Subak Soka, Subak Gading Wani, dan Subak Amerta. Dasar pertimbangan : (1) Subak-subak tersebut merupakan subak yang mendapat bantuan teknologi mesin rice transplanter dari pemerintah. (2) Subak-subak tersebut merupakan beberapa tempat terjadinya proses adopsi teknologi mesin rice trasplanter, dan (3) Belum pernah ada penelitian serupa di tempat penelitian.

\subsection{Jenis dan Sumber Data}

Data penelitian ini adalah kualitatif dan kuantitatif. Sumber data penelitian adalah data primer dan data sekunder.

\subsection{Metode Pengumpulan Data}

Pengumpulan data dalam penelitian ini melalui wawancara, observasi dan studi pustaka. Wawancara merupakan teknik pengumpulan data primer dengan mengajukan 
pertanyaan yang sistematis dan langsung kepada responden yang ditentukan dengan menggunakan alat bantu pedoman wawancara. Observasi merupakan proses untuk memperoleh data dari tangan pertama dengan mengamati orang dan tempat pada saat dilakukan penelitian (Sugiyono, 2015A). Studi pustaka merupakan kegiatan untuk mendapatkan informasi data secara teoritis melalui buku buku ilmiah, laporan penelitian, karangan-karangan ilmiah, tesis, disertasi, sumber-sumber tertulis dan lainlain yang berkaitan dengan penelitian.

\subsection{Sampel dan Informan Kunci}

Sampel dalam penelitian ini berjumlah 89 orang Teknik pengambilan sampel menggunakan teknik proportional sampling. Menurut Sugiyono (2003) Proportional sampling adalah pengambilan sampel yang memperhatikan pertimbangan unsur-unsur atau kategori dalam populasi penelitian.. Informan kunci dalam penelitian ini berjumlah 11 orang. Penentuan informan kunci atas dasar pertimbangan : (1) Pengurus subak. (2) Mereka menguasai atau memahami subak bersangkutan. (3) Mereka mempunyai cukup waktu untuk diwawancarai.

\subsection{Variabel dan Pengukuran Variabel}

Variabel-variabel yang dianalisis dalam penelitian ini adalah : (1) Tahapan adopsi mesin rice transplanter ; (2) Faktor yang berkaitan dengan tahapan adopsi. Pengukuran variabel-variabel dalam penelitian ini dengan menggunakan skor.

\subsection{Instrumen Penelitian}

Instrumen penelitian merupakan alat ukur yang digunakan untuk mengumpulkan data agar pekerjaannya lebih mudah dan hasilnya lebih baik, sehingga mudah diolah (Arikanto, 2013). Instrumen penelitian yang digunakan dalam penelitian ini adalah kuesioner, pedoman wawancara serta menggunakan analisis deskriptif kualitatif. Kuesioner adalah daftar pertanyaan yang dikirim kepada responden baik secara langsung maupun tidak langsung. Pedoman wawancara merupakan inti-inti yang dapat ditarik dari jawaban-jawaban wawancara sebelumnya, kemudian inti-inti dari jawaban tersebut akan dinyatakan kembali dalam melakukan wawancara mendalam terhadap responden atau narasumber. Analisis deskriptif kualitatif merupakan cara untuk menggambarkan tentang ciri-ciri responden dan variabel penelitian.

Kuesioner penelitian diuji melalui uji validitas dan uji reliabilitas. Menurut Sugiyono (2015B) validitas merupakan alat ukur yang digunakan untuk mendapatkan data (mengukur) itu valid, dengan kata lain instrumen tersebut dapat digunakan untuk mengukur apa yang seharusnya diukur. Menurut Sujarweni (2014) Reliabilitas merupakan ukuran suatu kestabilan dan konsistensi responden dalam menjawab hal yang berkaitan dengan kontruk-kontruk pertanyaan yang merupakan dimensi suatu variabel dan disusun dalam bentuk kuesioner.

Hasil uji validitas didapat bahwa dari 16 pernyataan kuesioner faktor yang berkaitan dengan tahapan adopsi petani di enam subak di Kabupaten Tabanan dinyatakan valid karena memiliki nilai $r$ hitung lebih tinggi dari $r$ tabel $(0,175)$ dengan nilai $r$ hitung tertinggi $(0,726)$. Uji reliabilitas ini diperoleh nilai alpha cronbach untuk kuesioner faktor-faktor yang berkaitan dengan tahapan adopsi petani di enam subak di Kabupaten Tabanan adalah 0,843.Berdasarkan hasil uji reliabilitas maka kuesioner dinyatakan konsisten. 


\subsection{Metode Analisis Data}

Metode analisis yang digunakan untuk menelaah seluruh data dalam penelitian adalah dengan menggunakan analisis deskriptif kualitatif. Variabel imperik yang digunakan dinarasikan dalam bentuk pernyataan positif, kemudian diberi skor 1sampai 5 berdasarkan tanggapan dari responden terhadap pernyataan yang telah diberikan.

\section{Hasil dan Pembahasan}

\subsection{Tahapan Adopsi Teknologi Mesin Rice Transplanter}

\subsubsection{Pengetahuan}

Pengetahuan seorang individu dapat mempengaruhi proses adopsi suatu inovasi. Jika individu mengetahui akan inovasi tersebut dan tahu akan keberadaannya, maka kemungkinan individu tersebut akan mencoba mengadopsi inovasi yang menguntungkan bagi dirinya.

Hasil penelitian menunjukan bahwa $100 \%$ responden dalam penelitian mengetahui tentang teknologi mesin rice transplanter secara umum. Pengetahuan responden tentang teknologi mesin rice transplanter tergolong tinggi. Anggota subak yang mendapatkan bantuan mesin rice transplanter mendapat pengetahuan tentang inovasi melalui program penyuluhan diselenggarakan oleh Dinas Pertanian Tanaman Pangan Provinsi Bali.

Pengetahuan tentang fungsi teknologi mesin rice transplanter menunjukan bahwa responden dalam penelitian ini belum sepenuhnya mengetahui fungsi teknologi mesin rice transplanter. Sebagian besar dari responden sudah mengetahui apa sebenarnya fungsi mesin tersebut. sebanyak $88,76 \%$ responden sudah mengetahui tentang fungsi teknologi mesin rice transplanter. Pengetahuan responden tentang fungsi teknologi mesin rice transplanter tergolong tinggi.

Pengetahuan tentang cara pengaplikasian teknologi mesin rice transplanter, responden yang tahu cara pengaplikasiannya sebanyak $22,47 \%$ responden. Responden yang tidak tahu sebanyak $77,53 \%$ responden. Pengetahuan responden tentang cara pengaplikasian teknologi mesin rice transplanter tergolong rendah. Hal tersebut karena teknologi mesin rice transplanter merupakan inovasi baru, sehingga petani membutuhkan lebih banyak waktu dan proses agar bisa tahu bagaimana cara pengaplikasian teknologi tersebut di lapangan.

\subsubsection{Persuasi}

Tahap persuasi terjadi ketika individu memiliki sikap positif atau negatif terhadap inovasi. Sikap ini tidak secara langsung akan menyebabkan apakah individu tersebut akan menerima atau menolak suatu inovasi. Suatu individu akan membentuk sikap ini setelah dia tahu tentang inovasi, maka tahap ini berlangsung setelah knowledge stage dalam proses keputusan inovasi (Rogers, 1983).

Hasil penelitian mengenai sikap responden di enam subak di Kabupaten Tabanan menunjukan bahwa sebanyak $22,47 \%$ responden memiliki sikap positif terhadap teknologi mesin rice transplanter. Sebanyak 77,53\% responden memiliki sikap negatif terhadap teknologi mesin rice transplanter.

\subsubsection{Keputusan}

Pada tahapan ini individu membuat keputusan apakah menerima atau menolak suatu inovasi untuk di implementasikan. Berdasarkan hasil penelitian menunjukan bahwa keputusan responden adalah menerima inovasi untuk diimplementasikan atau 
dicobakan sebanyak 12,36\% responden, sedangkan yang belum menerima sebanyak $87,64 \%$ responden. Masalah yang mendasari sehingga sedikit responden yang memutuskan mencoba inovasi yaitu dari segi tingkat kesulitan inovasi yang tergolong sangat sulit. Teknologi mesin rice transplanter tergolong inovasi baru sehingga penguasaan petani terhadap inovasi tersebut belum maksimal. Faktor sulitnya membawa dan memindahkan teknologi mesin rice transplanter ke lahan satu ke lahan yang lainnya, 88,64\% menganggap teknologi mesin rice transplanter kurang praktis untuk dilahan mereka. Faktor alih fungsi lahan sawah menjadi tegalan juga mempengaruhi keputusan petani dalam menerapkan inovasi tersebut. Lahan sawah tidak ada maka teknologi mesin rice transplanter menjadi tidak dibutuhkan.

Tabel 1.

Distribusi Responden Berdasarkan Keputusan Petani Terhadap Teknologi Mesin Rice Transplanter

\begin{tabular}{|c|c|c|c|}
\hline \multirow{2}{*}{ Pendapat responden } & \multicolumn{2}{|c|}{ Banyak Petani } & \multirow{2}{*}{ Jumlah } \\
\hline & Menggunakan & Tidak Menggunakan & \\
\hline Mudah & 6 & 14 & 20 \\
\hline Tidak Mudah & 5 & 64 & 69 \\
\hline Jumlah & 11 & 78 & 89 \\
\hline
\end{tabular}

Dari data diatas, maka dapat disimpulkan keputusan responden ingin menggunakan teknologi mesin rice transplanter dilapangan dipengaruhi oleh kesulitan inovasi digunakan dilapangan.

\subsubsection{Implementasi}

Pada tahap implementasi, sebuah inovasi dicoba untuk dipraktekkan untuk melihat fungsi dan kegunaan yang melekat pada inovasi dan menilai apakah inovasi sesuai dengan kebutuhan individu atau sebaliknya. Hasil penelitian menunjukan implementasi teknologi mesin rice transplanter hanya sebanyak 11 orang petani atau $12,36 \%$ responden yang mencoba inovasi dilapangan. Sebanyak 78 orang petani atau $87,64 \%$ responden belum berkeinginan untuk mengimplementasikan inovasi untuk diuji cobakan

Menurut 12,36\% responden yang mencoba inovasi dilapangan, penggunaan teknologi mesin rice transplanter tergolong sangat sulit. Hal itu disebabkan 12,36\% responden tersebut belum terbiasa menggunakkan teknologi mesin rice transplanter, karena inovasi tersebut tegolong baru. Membawa dan memindahkan teknologi mesin rice transplanter dari lahan satu ke lahan lain juga menjadi kendala dalam mencobakan inovasi, menurut responden yang mencobakan. Jadi, dari $12,36 \%$ responden yang mencoba inovasi menyatakan inovasi kurang praktis dan efektif, sehingga petani menjadi tidak berkeinginan melanjutkan mengimplementasikan teknologi mesin rice transplanter. 
Tabel 2.

Distribusi Responden Berdasarkan Implementasi Petani Terhadap Teknologi Mesin Rice Transplanter untuk di Uji Cobakan

\begin{tabular}{clcc}
\hline No & \multicolumn{1}{c}{ Variabel Imperik } & $\begin{array}{c}\text { Jumlah responden } \\
\text { (orang) }\end{array}$ & Persentase (\%) \\
\hline 1. & $\begin{array}{l}\text { Inovasi diimplementasikan untuk di } \\
\text { uji cobakan }\end{array}$ & 11 & 12,36 \\
2. $\begin{array}{l}\text { Inovasi tidak diimplementasikan } \\
\text { untuk di uji cobakan }\end{array}$ & 78 & 87,64 \\
\hline \multicolumn{1}{c}{ Total } & 89 & 100,00 \\
\hline
\end{tabular}

\subsubsection{Konfirmasi}

Konfirmasi merupakan tahap implementasi yang berkelanjutan, dimana tahap ini merupakan tahap lanjutan dari tahap sebelumnya. Tahap konfirmasi terjadi bila individu sudah percaya akan inovasi dan berkelanjutan dalam menggunakan inovasi tersebut. Hasil penelitian menunjukkan bahwa tidak ada anggota subak yang mencoba melanjutkan mengimplementasi teknologi mesin rice transplanter, hal tersebut diungkapkan dari penuturan para pekaseh di subak tempat penelitian. Seperti yang diterangkan diatas bahwa hal tersebut terjadi karena kurangnya penguasaan petani terhadap teknologi, kurang sesuainya teknologi dengan lingkunngan serta alih fungsi lahan menjadi tegalan.

\subsection{Faktor yang Berkaitan dengan Adopsi Inovasi}

\subsubsection{Sifat Inovasi}

Berdasarkan hasil wawancara peneliti dengan responden, peneliti mendapatkan informasi bahwa informasi ilmiah yang melekat pada sistem inovasi teknologi mesin rice transplanter diketahui sebanyak $88,76 \%$ responden, sedangkan yang tidak tahu sebanyak 11,24\% responden. Responden yang tidak mengetahui informasi ilmiah yang melekat di inovasi tersebut, karena responden tersebut tidak mengikuti penyuluhan.

Teknologi mesin rice transplanter memiliki nilai-nilai keunggulan yang terbagi menjadi keunggulan teknis, ekonomi, sosial dan budaya, dan politis. Berdasarkan hasil penelitian sebanyak $88,76 \%$ responden mengetahui pasti tentang nilai-nilai keunggulan teknologi mesin rice transplanter. Sebanyak $11,24 \%$ responden menjawab tidak tahu pasti mengenai keunggulan dari teknologi mesin rice transplanter. Pendapat tersebut dilandasi karena tidak ketahuan mereka serta tidak ikut berpartisipasinya petani tersebut dalam penyuluhan oleh Dinas Pertanian Tanaman Pangan Provinsi Bali.

Tingkat kesulitan teknologi mesin rice transplanter untuk dicobakan berdasarkan hasil jawaban 89 responden menunjukan bahwa tingkat kesulitan diuji cobakan yaitu sangat sulit, dilihat dari perolehan skor 118 dari total skor maksimal 445, dan termasuk kedalam kelas 89-160. Jadi, dari hal tersebut sedikit responden yang berkeinginan mencobakan inovasi. Sifat inovasi yang mempengaruhi adopsi inovasi teknologi mesin rice transplanter adalah kesesuaian inovasi dengan lingkungan setempat. Kesesuaian inovasi teknologi mesin rice transplanter di enam subak di tempat penelitian adalah sebagai berikut. 


\section{Secara Fisik}

Topografi pada subak tempat penelitian peneliti, lahan cenderung sempit, berbukit, memiliki banyak pematang sawah dengan bentuk melengkung, berkelok, dan berundak. Kondisi tersebut membuat petani kesulitan menerapkan teknologi mesin rice transplanter dilahan mereka. Teknologi mesin rice transplanter akan lebih efektif dilakukan dilahan yang datar dan lahan yang cukup luas.

2. Sosial-Budaya

Hasil penelitian menunjukan bahwa sosial-budaya di enam subak yang menjadi tempat penelitian masih menggunakan penanaman konvensional yang menggunakan tenaga kerja(buruh nandur).

\subsubsection{Persepsi Sasaran atau Pengguna Inovasi}

Individu dalam memahami suatu inovasi dapat melalui proses persepsi. Persepsi adalah stimulus yang mengenai individu itu kemudian diorganisasikan dan diinterpretasikannya sehingga individu menyadari tentang apa yang diinderanya (Walgito, 2004). Melalui proses persepsi, suatu inovasi teknologi baru yang ditangkap oleh indera itu bisa dikatakan sebagai sesuatu yang berarti dan bermanfaat baginya ataupun sebaliknya .

Berdasarkan hasil penelitian persepsi petani terhadap teknologi mesin rice transplanter dapat menghemat biaya produksi, memperoleh skor 238 dari total skor maksimal berjumlah 445. Perolehan skor tersebut termasuk dalam skor $>231-302$ sehingga termasuk dalam kategori cukup baik. Persepsi petani terhadap teknologi mesin rice transplanter dapat meningkatkan hasil panen memperoleh skor 250 dari responden, dari total skor maksimal 445. Perolehan skor tersebut termasuk dalam skor $>231-302$ sehingga termasuk dalam kategori cukup baik. Persepsi petani terhadap teknologi mesin rice transplanter dapat menghemat waktu pengerjaan memperoleh skor 270 dari responden, dari total skor maksimal 445. Perolehan skor tersebut termasuk dalam skor >231-302 sehingga termasuk dalam kategori cukup baik. Persepsi petani terhadap teknologi mesin rice transplanter dapat sebagai pengganti tenaga kerja memperoleh skor 320 dari responden, dari total skor maksimal 445. Perolehan skor tersebut termasuk dalam skor $>302-373$ sehingga termasuk dalam kategori baik.

Persepsi petani terhadap teknologi mesin rice transplanter dari tingkat kesulitan teknologi mesin rice transplanter dalam menghidupkan adalah 89 responden berpendapat tingkat kesulitannya tergolong mudah, yang dilihat dari perolehan skor 309 dari total skor maksimal 445 dan termasuk kedalam kelas $>302-373$. Persepsi petani tentang tingkat kesulitan teknologi mesin rice transplanter dalam pemasangan bibit adalah 89 responden berpendapat tingkat kesulitannya tergolong cukup mudah, yang dilihat dari perolehan skor 299 dari total skor maksimal 445 dan termasuk pada kelas $>$ 231-302. Persepsi petani tentang tingkat kesulitan teknologi mesin rice tranplanter dicobakan adalah sangat sulit, yang dilihat dari perolehan skor 118 dari total skor maksimal 445 dan termasuk kedalam kelas 89-160.

\subsubsection{Sikap Sasaran atau Pengguna Inovasi}

Berdasarkan hasil penelitian menunjukkan bahwa sikap responden ingin mengimplementasikan teknologi mesin rice transplanter tergolong sangat rendah karena memperoleh skor 155 dari skor 445 dan termasuk ke dalam kelas 89-160. Hal tersebut dipengaruhi berbagai banyak faktor diantaranya penguasaan petani terhadap inovasi, kesesuaian lingkungan dengan inovasi, dan alih fungsi lahan menjadi tegalan. 
Sikap responden akan kebutuhan teknologi mesin rice transplanter di lahan usahatani petani tergolong sangat rendah karena memperoleh skor 143 dari skor 445 dan termasuk ke dalam kelas 89-160. Hal tersebut terjadi karena para petani di tempat penelitian masih menerapkan penanaman konvensional yang menggunakan tenaga kerja (buruh nandur). Sosial-budaya yang masih di terapkan petani tersebut, mempengaruhi kebutuhan petani terhadap inovasi teknologi mesin rice transplanter.

\subsubsection{Perilaku Sasaran atau Pengguna Inovasi}

Perilaku adalah tindakan atau aktivitas dari manusia itu sendiri yang mempunyai bentangan yang sangat luas. Jadi dapat disimpulkan bahwa yang dimaksud perilaku manusia adalah semua kegiatan atau aktivitas manusia, baik yang diamati langsung, maupun yang tidak dapat diamati oleh pihak luar (Notoatmodjo, 2003).

Berdasarkan hasil penelitian menunjukan bahwa prilaku petani dalam arti ingin menggunakan teknologi mesin rice transplanter tergolong rendah, hanya $12,36 \%$ responden yang menerima inovasi, sedangkan yang belum menerima sebanyak $87,64 \%$ responden. Hal yang mempengaruhi petani tidak mengadopsi teknologi mesin rice transplanter, karena para petani lebih memilih menggunakan penanaman konvensional dan teknologi mesin rice transplanter tergolong baru sehingga penguasaan petani terhadap inovasi tersebut belum maksimal. Sulitnya membawa dan memindahkan teknologi mesin rice transplanter ke lahan satu ke lahan yang lainnya juga mempengaruhi keputusan petani dalam menerapkan inovasi, mereka menganggap teknologi mesin rice transplanter kurang praktis untuk dilahan petani.

\subsubsection{Penggunaan Teknologi Mesin Rice Transplanter}

Hasil penelitian menunjukkan bahwa hanya $12,36 \%$ responden yang pernah menggunakan teknologi mesin rice transplanter untuk dicobakan. Sebanyak 78 responden atau $87,64 \%$ responden belum berkeinginan untuk mengimplementasikan inovasi untuk diuji cobakan. Hal tersebut menunjukkan bahwa penggunaan inovasi oleh sasaran rendah.

Menurut petani yang pernah menggunakan di lahan, penggunaan teknologi mesin rice transplanter tergolong sangat sulit. Petani tersebut belum terbiasa menerapkannya pada lahan sawah, sehingga hasilnya tidak sesuai dengan kebutuhan petani. Selain itu, $12,36 \%$ responden menyatakan bahwa dalam membawa dan memindahkan teknologi di lahan juga menjadi kendala dan kesulitan petani. Hal itu disebabkan lahan sawah petani berbukit, berundag-undag dan memiliki banyak terasering. Jadi, 12,36\% responden setelah mencobakan menganggap inovasi kurang praktis dan efektif, sehingga petani menjadi tidak melanjutkan penggunaan teknologi mesin rice transplanter pada lahan usahatani.

\section{Simpulan dan Saran}

\subsection{Simpulan}

Pada pembahasan, tahapan adopsi teknologi mesin rice transplanter hanya sampai pada tahap mencobakan inovasi. Sebanyak 12,36\% responden yang pernah mencoba rice transplanter, tetapi hasil yang didapat tidak sesuai dengan kebutuhan petani dan memutuskan untuk tidak melanjutkan kembali meggunakan inovasi. Jadi tahapan adopsi teknologi mesin rice transplanter sampai pada tahap mencobakan inovasi dan tidak berlanjut ke tahap konfirmasi untuk melanjutkan inovasi. 
Faktor yang berkaitan dengan adopsi teknologi, yaitu sifat inovasi yang diketahui benar sebanyak $88,76 \%$ responden. Persepsi petani tentang kegunaan dan manfaat teknologi tergolong cukup baik (skor 758 termasuk kelas >695-909) dan persepsi tentang kemudahan teknologi tergolong cukup sulit (skor 726 termasuk kelas $>695$ 909). Sikap sasaran ingin mengimplementasikan serta kebutuhan akan teknologi tergolong sangat rendah (skor 155 dan skor 143 termasuk dalam kelas 89-160). Perilaku sasaran dalam menerima inovasi tergolong rendah, hanya $12,36 \%$ responden yang menerima. Penggunaan inovasi, hanya $12,36 \%$ responden yang menggunakan inovasi untuk dicobakan.

\subsection{Saran}

Mengingat fakta menunjukkan bahwa tahapan adopsi teknologi yang mencapai implementasi yang masih rendah dan tidak berkelanjutan, saran yang bisa peneliti berikan agar lebih banyak petani mampu mengimplementasi teknologi mesin rice transplanter dan berkelanjutan adalah sebagai berikut :

1. Pemerintah perlu meningkatkan pendidikan petani tentang teknologi mesin rice transplanter dengan penyuluhan-penyuluhan dan studi banding. Sehingga dengan meningkatnya pendidikan petani tentang teknologi mesin rice transplanter diharapkan mampu mengimplementasikan teknologi dengan baik dan berkelanjutan.

2. Saran yang bisa peneliti berikan kepada petani adalah penguatan motivasi dalam menggunakan teknologi mesin rice transplanter dengan mencoba kembali inovasi serta berkunjung atau belajar ke subak-subak lain yang sudah mampu menggunakan teknologi rice transplanter dengan baik.

\section{Ucapan Terimakasih}

Bapak I Nyoman Winata, I Wayan Adi Suryanta, I Wayan Sumawa Ariyana, I Nyoman Sugita, I Made Suka Artawa, I Ketut Suidarna selaku pekaseh subak di enam subak di Kabupaten Tabanan, peneliti mengucapkan terimakasih karena sudah memberikan ijin mengadakan penelitian. Peneliti juga mengucapkan terimakasih kepada seluruh informan kunci serta anggota subak di enam subak di Kabupaten Tabanan yang telah banyak meluangkan waktu serta informasi mengenai penelitian ini sehingga skripsi ini dapat diselesaikan dengan baik.

\section{Daftar Pustaka}

Arikunto, S. 2013. Prosedur Penelitian: Suatu Pendekatan Praktik. Rineka. Jakarta

Badan Pusat Statistik. 2015. Produktivitas Padi di Indonesia Pada Tahun 2015. Diunduh pada https://www.bps.go.id/Brs/view/id/1157 diakses pada tanggal 22 Januari 2018.

Kadarsan. 2011. Pengertian Usahatani. Diunduh pada http://www.pengertian menurutparaahli.net/pengertian-usahatani-menurut-para-ahli/ diakses pada tanggal 22 Januari 2018

Notoatmodjo. 2003. Pendidikan dan Perilaku Kesehatan. Rineka Cipta. Jakarta

Rogers, Everett M. 1983, Diffusion of Innovations. The Free Press. London

Sugiyono. 2003. Metode Penelitian Bisnis. Pusat Bahasa Depdiknas. Bandung 2015A. Metode Penelitian Pendidikan: Pendekatan Kuantitatif, Kualitatif,

dan $R \& D$. Alfabeta. Bandung .2015B. Metode Penelitian Kuantitatif Kualitatif R\&B. Aflabeta. Bandung 
Sujarweni, V. Wiratna. 2014. Metode Penelitian : Lengkap, Praktis, dan Mudah Dipahami. Pustaka Baru Press. Yogyakarta

Walgito. 2004. Pengantar Psikologi Umum. ANDI OFFSET. Yogyakarta 